\title{
CAPITAL ACCUMULATION AND UNEMPLOYMENT: A TALE OF TWO "CONTINENTS"*
}

\author{
Jim MALLEY AND Thomas Moutos
}

In contrast to much recent work regarding the causes of European unemployment, in this paper, we emphasise the importance of capital accumulation. But unlike the few previous studies which have examined the relationship between capital stock and unemployment, we argue that what matters for the evolution of employment [and the unemployment rate] is not the absolute growth rate of a country's capital stock, but its evolution relative to other countries' capital stock. The empirical importance of the above statement is demonstrated using quarterly time-series data from 1961-1995 for Germany, Japan and the United Kingdom.

\section{INTRODUCTION}

The received wisdom regarding the causes of the historically high unemployment rates in Europe during the last twenty years has recently been reaffirmed: “...generous unemployment benefits that are allowed to run on indefinitely...; high unionization with wages bargained collectively and no coordination between either unions or employers in wage bargaining; high overall taxes impinging on labour...; poor educational standards at the bottom end of the labour market" [Nickell, 1997, p.72]. Accordingly, it is suggested that to fight unemployment, the European countries should (a) reduce the duration for which unemployment benefits are payable (b) erode the relative value of the minimum wage (c) restructure the payroll tax system (d) foster competition in product and labour markets (e) improve training and

* We would like to thank Julia Darby, Antonios Demos, Jacques Dräze, Apostolis Philippopoulos and Ulrich Woitek for helpful comments and suggestions. This paper was written while Jim Malley was on sabbatical at the Athens University of Economics and Business [AUEB]. He would also like to thank the AUEB, the Carnegie Trust for the Universities of Scotland and the John Robertson Bequest for financial assistance which made this visit possible. 
(f) offer the unemployed the option of turning their benefits into employment vouchers [Alogoskoufis et al., 1995, p.129-130]. Others are even more emphatic about the roots of the evil: “...the specter of unemployment that is haunting Europe will not be exorcised unless governments are prepared to undertake major reforms of the institutional setup of the labour market" [Siebert, 1997, p.53].

What the above mentioned studies and many others [c.f. Nickell, 1998, Phelps and Zoega, 1998 and Sargent, 1998] have in common is the absence of any role for the capital stock as a determinant of unemployment. In their influential treatise on unemployment, Layard, Nickell and Jackman, 1991 - LNJ [1991] hereafter - provide a justification for this omission based on a "stylized fact": the unemployment rate is untrended over the very long-term. They interpret this as suggesting that in the longterm, a country's capital stock and productivity have no impact on its unemployment rate. Otherwise unemployment should be negatively trended given the large increases in capital stock and productivity during the last century. Additionally, they show that in the context of a union model [p. 107], equilibrium unemployment is independent of the amount of capital per capita in the economy if the production function is CobbDouglas and the benefit replacement ratio is constant.

The relationship between the capital stock and the unemployment rate has attracted the attention of a small number of economists [the earliest one being Malinvaud, 1980]. Bean [1994] provides a summary of the earlier work in this area which is mainly based on the idea of limited ex-post substitutability between capital and labour. In this work, employment is constrained by the amount of the existing capital stock. Survey evidence on capacity utilization has been used by Sneessens and Dräze [1986] to support the idea that capital shortages create a technological constraint on 
employment. Nevertheless, later studies [see, Dräze and Bean, 1990], have questioned the assumption of limited ex-post factor substitutability and Bean [1994] concludes that capital shortages cannot be the main explanation for the rise in European unemployment. This conclusion has been challenged by two recent studies.

First, Rowthorn [1996] uses a "battle of the mark-ups" or a "competing claims" model [see Rowthorn, 1977, Blanchard, 1986, Layard and Nickell, 1986 and Carlin and Soskice, 1990] type model to argue that an increase in the capital stock reduces the ability of firms to raise prices since it creates - ceteris paribus - excess capacity. It also leads to better trade performance, which allows the real exchange rate to appreciate and real domestic income to increase. The conflict over income distribution is thus lessened and a stable rate of inflation can be achieved at a lower unemployment rate. Rowthorn's empirical analysis provides some support for this thesis.

Second Gordon [1997] finds that the countries which experienced the largest slowdowns in the growth rate of capital per potential labour hour faced the greatest increases in the unemployment rate. He also concluded that the European countries in the 1990s do not have enough capital to equip all the employees who would have had a job if unemployment rates in Europe had remained at the level of the late 1970s. The basic mechanism which Gordon uses to explain these findings is a version of the "battle-of-the-mark-ups". In this framework a wage-setting shock [due, for example, to an exogenous increase in the bargaining power of trade unions] results, initially, in a decline in employment and an increase in labour productivity. However, the marginal product of capital will fall, as the fixed stock of capital is now combined with a smaller labour input. This will in turn reduce the demand for capital and a period of 
disinvestment will follow resulting in a downward shift of the "labour demand curve". If the production function is Cobb-Douglas, Gordon shows that the new equilibrium position will involve the original level of labour productivity and even lower employment. Consequently, the traditionally expected [positive] trade-off between unemployment and productivity would not be observed.

The main point of this paper is that in an international context, what matters for the evolution of employment [and the unemployment rate] is not the absolute growth rate of a country's capital stock, but its evolution relative to other countries' capital stock. In other words, this paper explains the medium- to long-term variations [caused by differential rates of capital accumulation] around the untrended very long-term unemployment rate brought to the attention of the profession by LNJ [1991]. To understand the intuition generating such a conclusion, consider an oligopolistic setting in which domestic firms are competing with foreign firms. If firms compete in quantities [the Cournot-Nash solution], then increases in the domestic capital stock [which increase labour productivity] will - by reducing the marginal cost of domestic firms - increase domestic output and reduce foreign output and employment. However the effect on domestic employment is ambiguous since it depends on the net result of the employment gains associated with higher domestic output and the employment loses [at the same level of output] due to increased productivity. By contrast, increases in the foreign capital stock, would result in decreases in the marginal cost of foreign firms and in reductions of domestic output and employment. In this sense the trade-off between unemployment and productivity [or the capital stock] may even be negative. A country may need high growth rates in its capital stock to avoid the loss 
of market share which would be a result of increases in foreign capital stock [and productivity].

\section{Figure 1. Plot of Unemployment Rate \& Growth in Relative Capital Stock}

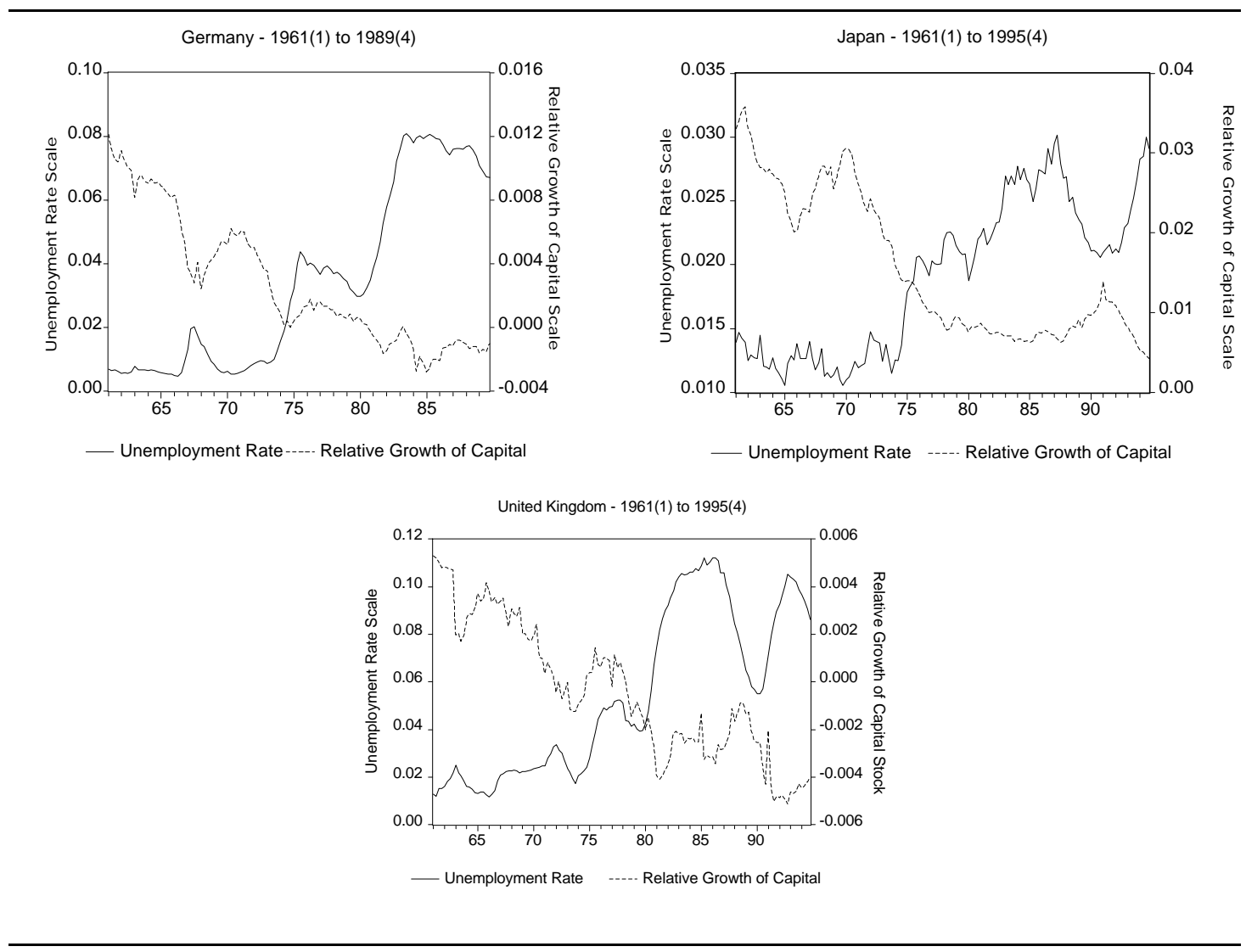

Figure 1 illustrates the empirical importance of the above statement very clearly. Given the widely differing experience between Europe and Japan over unemployment on the one hand, and the growth rate of the capital stock, on the other, we choose to focus our empirical investigation on three countries: Germany, United Kingdom [as representatives of the European experience] and Japan. For each of the above countries, the vertical axes in Figure 1 measures the unemployment rate [left axis] and the difference in the growth rate between each country's capital stock and the weighted average of the rest of the OECD's capital stock [right axis] ${ }^{1}$. We term the variable on the right axis "growth rate in the relative capital stock". For each of 
the three countries there is a clear negative relationship between the unemployment rate and the growth rate in the relative capital stock. In fact, this relationship holds for the majority of the 20 OECD countries for which data are available ${ }^{2}$. The only exceptions are Belgium, Ireland, Switzerland and the U.S.. For the last three of these countries this is perhaps explained by the relatively large [either inward or outward] migration they have experienced ${ }^{3}$.

Recently, Blanchard [1998] argued that the failure of unemployment to decrease in Continental Europe since the mid 1980s - despite the substantial decreases in wages relative to underlying factor productivity - must be due to a downward movement of the labour demand curve. Blanchard suggests two explanations [and provides some weak evidence, see, Blanchard, 1997] for the drop in labour demand. The first rests on a shift in the distribution of rents. Tighter corporate governance and weaker unions many have allowed firms which suffered from feather bedding and excess employment to shed labour. The second explanation is based on technological bias: firms in Continental Europe have adopted more capital intensive methods of production. Our explanation for the drop in labour demand by European firms as a result of faster capital accumulation in other countries is supportive of Blanchard's emphasis on adverse shifts in the labour demand curve.

The rest of this paper is organised as follows. In the next Section we first construct a simple two-country model to show the partial equilibrium effects of changes in the domestic and foreign capital stocks. Then we discuss the macroeconomic implications arising from relaxing some of the partial equilibrium assumptions. In Section 3, we estimate the relationship between the unemployment rate and the growth in relative capital accumulation for Germany, Japan and the United 
Kingdom. In Section 4, we test whether the strong and statistically significant negative relationship that we find between the two variables is an artifact of either missing variables and/or of high correlation of the relative capital stock variable with aggregate demand measures. Finally Section 5 contains concluding comments.

\section{THEORETICAL CONSIDERATIONS}

In this Section we present an imperfectly competitive model in which - ceteris paribus - an increase in the foreign capital stock results in decreases in domestic employment and - assuming a vertical labour supply curve - in an increase in the unemployment rate. The model is a variant of the partial equilibrium models used in the strategic trade policy literature [see, for example, Brander and Spencer, 1985, Helpman and Krugman, 1989] $]^{4}$. We then use the results of this model to draw some implications regarding the effects of domestic and foreign capital accumulation in a macroeconomic framework.

\subsection{CAPITAL STOCKS AND EMPLOYMENT IN PARTIAL EQUILIBRIUM}

Consider a two country model with each economy consisting of many sectors. We first examine one sector in isolation. We assume that there is a unified world market for the product of this sector in which $n$ [identical] domestic and $n$ [identical] foreign firms behave as Cournot oligopolists. The market demand curve facing domestic and foreign firms in this sector is

$$
P=\alpha-\beta\left(n X_{1}+n X_{2}\right)
$$

where $P$ is the price of the product and $X_{i} ; i=1,2$ is the output [and sales] of each of the $n$ domestic and $n$ foreign firms, respectively. The capital stock $K_{i}$, which each firms uses is taken as exogenous and the user cost of capital is denoted by $r$. We assume 
further that both sets of firms have similar cost structures. In particular, we assume that there are economies of scale which arise from the existence of a fixed cost in terms of labour which must be incurred to start producing.

This is expressed as

$$
N_{i}=\gamma_{i}+\delta_{i}\left(K_{i}\right) X_{i}, \quad \delta_{i}^{\prime}\left(K_{i}\right)<0, \quad i=1,2
$$

where $N_{i}$ is the amount of labour required to produce $\mathrm{X}_{\mathrm{i}}$ units of output by each firm in country $i, \gamma_{\mathrm{i}}$ is the fixed cost of labour input in country $i$, and $\delta_{\mathrm{i}}\left(K_{i}\right)$ is the marginal input-output coefficient which depends [negatively] on the capital stock used by each firm. For any given level of the capital stock, equation (2) implies that the marginal cost is constant but the average cost is declining. The term $\delta_{\mathrm{i}}\left(K_{i}\right)$ captures the extent to which a higher capital stock succeeds in increasing the productivity of labour.

The profit function of each firm can be written as

$$
\pi_{i}=P X_{i}-\left[\gamma_{i}+\delta_{i}\left(K_{i}\right) X_{i}\right] w_{i}-r_{i} K_{i}, \quad i=1,2
$$

where $w_{i}$ stands for the given wage rate. The Cournot-Nash solution to this oligopoly game predicts that the output level of each domestic and foreign firm will be equal to

$$
\begin{aligned}
& X_{1}=\frac{\alpha+n w_{2} \delta_{2}\left(K_{2}\right)-(n+1) w_{1} \delta_{1}\left(K_{1}\right)}{\beta(2 n+1)} \\
& X_{2}=\frac{\alpha+n w_{1} \delta_{1}\left(K_{1}\right)-(n+1) w_{2} \delta_{2}\left(K_{2}\right)}{\beta(2 n+1)} .
\end{aligned}
$$

From equations (4) and (5) we observe that an increase in the domestic firms' capital stock will increase their output and reduce the output of their foreign rivals. The effects of changes in the capital stock on employment are not so clear-cut however. We find that 


$$
\begin{gathered}
\frac{d N_{1}}{d K_{1}}=\frac{\delta_{1}^{\prime}\left(K_{1}\right)\left[\alpha+n w_{2} \delta_{2}\left(K_{2}\right)-2(n+1) w_{1} \delta_{1}\left(K_{1}\right)\right]}{\beta(2 n+1)} \underset{<0}{>} \frac{d N_{2}}{d K_{2}}=\frac{\delta_{2}^{\prime}\left(K_{2}\right)\left[\alpha+n w_{1} \delta_{1}\left(K_{1}\right)-2(n+1) w_{2} \delta_{2}\left(K_{2}\right)\right]}{\beta(2 n+1)}>_{<}^{>} 0 \\
\frac{d N_{1}}{d K_{2}}=\frac{n w_{2} \delta_{2}^{\prime}\left(K_{2}\right) \delta_{1}\left(K_{1}\right)}{\beta(2 n+1)}<0 \\
\frac{d N_{2}}{d K_{1}}=\frac{n w_{1} \delta_{1}^{\prime}\left(K_{1}\right) \delta_{2}\left(K_{2}\right)}{\beta(2 n+1)}<0 .
\end{gathered}
$$

We observe that an increase in the capital stock of each domestic firm will result - ceteris paribus - in a reduction in employment for every foreign firm, whereas it has an ambiguous effect on domestic employment. This ambiguity stems from the fact that fewer workers are now needed to produce the old level of output. The increase in domestic output may thus not be large enough to provide employment for those that would lose their jobs if domestic output had remained constant. From equations (6) and (7) we can also observe that the higher is the number of firms, the more likely it becomes that $\left[d N_{1} / d K_{1}\right]$ and $\left[d N_{2} / d K_{2}\right]$ are positive. This follows since as the number of firms increases [i.e. as the situation becomes closer to perfect competition], the larger is the increase in the total output of domestic firms generated by a decrease in the marginal cost. Productivity increases or technical progress are thus more likely to lead to increases in domestic employment the larger is the degree of competition between firms.

On the basis of the above partial equilibrium results one may be tempted to conclude that equivalent increases in the capital stock of both domestic and foreign firms are not likely to result in increases in either domestic or foreign employment. 
Consider, for example, a symmetric case in which domestic and foreign firms are identical [i.e. $w_{1}=w_{2}=w, K_{l}=K_{2}=K, \delta_{1}\left(K_{1}\right)=\delta_{2}\left(K_{2}\right)=\delta(K)$ ]. Then we find that

$$
\frac{d N_{1}}{d K_{1}}+\frac{d N_{2}}{d K_{2}}=\frac{\delta^{\prime}(K)[\alpha-2 w \delta(K)]}{\beta(2 n+1)} \underset{<}{>} 0 .
$$

Even though this expression appears to be ambiguous, note that $\alpha$ denotes the [almost] maximum price which can be set in the market without sales [of all firms] dropping to zero whereas $w \delta(K)$ denotes the marginal cost. Since we can think of many people who would be willing to pay twice the going price for a box of matches rather than go without them and [we suspect] that Mercedes would be able to sell some cars even if it doubled its prices, it is very likely that $\alpha>2 w \delta(K)$. Consequently, we would expect that in this particular partial equilibrium setting equal increases in $K_{l}$ and $K_{2}$ would result in a fall in employment in the sector producing this good in both countries.

\subsection{MACROECONOMIC IMPLICATIONS}

The first thing that must be taken into account with respect to the previous analysis in a macroeconomic setting is the assumed constancy of the market demand curve [equation (1)]. If, following from the previous symmetric example, $K_{1}$ and $K_{2}$ increase by the same amount, from equations (4) and (5) we can deduce that $X_{1}$ and $X_{2}$ will increase. If the increase in output [and of the capital stock] is not restricted to a particular sector, the resulting increase in aggregate [real] income would affect at least the position [i.e. it would increase the value of parameter $\alpha$ ] of the market demand curve. Nevertheless it can be shown that the net effect on employment would still be [even within the confines of the particular example] ambiguous. 
This ambiguity becomes, however, less pronounced if we allow for unequal increases in the capital stocks of the two countries. Consider, for example an increase in the world capital stock that is unequally distributed between the domestic and the foreign country $\left[d K_{2}>d K_{1}\right]$. It is then obvious from equations (6) and (8) that - ceteris paribus - it becomes more likely that domestic employment will fall [equivalently, it becomes more likely that foreign employment will rise]. We therefore conclude that countries which enjoy faster growth rates in their capital stock than their trade partners are more likely - ceteris paribus - to experience employment increases.

We now relax the assumption of constant wages at home and abroad [i.e. the assumption of constant competitiveness]. Following LNJ [1991] we assume that there exists an upward sloping wage setting [WS] function which relates aggregate employment to the real wage [for a given labour supply]. Such a relationship is usually explained in terms of the increased ability that workers have to push up wages when the unemployment rate is low or alternatively by the observation that firms offer high wages when the unemployment rate is low. The latter is explained by the firm's desire to limit shirking and quits by their employees. The position of this schedule depends amongst other things - on labour productivity. A higher level of the capital stock is expected to shift the WS schedule upwards. LNJ [1991] argue that it is such increases in wage demands on the part of workers which offset the positive effects of a higher capital stock on employment. In our context, an increase in the foreign capital stock for a given level of the domestic capital stock - will have no effect on the position of the wage setting schedule. It will, nevertheless, effect a movement along this schedule, thereby only partly offsetting the negative effect on domestic employment. And to the extent that the upward shift of the foreign wage setting curve does not further erode 
the increase in competitiveness of the foreign country, there will be an increase in the domestic unemployment rate. Equiproportional increases in the domestic and foreign capital stock essentially move both countries upwards along a vertical long-run wagesetting curve. Real wages increase in both countries but the unemployment rate in the very long-term is unaffected. The analysis becomes only slightly more complicated if we allow both countries' capital stocks to grow but at unequal rates. In this case there would be an upward shift in the wage setting schedules of both countries and as long as the growth rate of the foreign country's capital stock is larger, the domestic [foreign] unemployment rate will be expected to increase [fall].

Up to this point we have assumed that the labour force is constant. It is obvious that an increase in the capital stock may induce a larger proportion of the population to enter the labour market, through its effects on wages described earlier ${ }^{5}$. In such a case even if the result of increases in the relative capital stock of the domestic country is increased employment, the unemployment rate may not fall ${ }^{6}$. In Section 4 we examine to what extent the evolution of competitiveness and the labour force can either augment or supplant the negative relationship appearing in Figure 1 between the unemployment rate and relative capital accumulation.

\section{EMPIRICAL LINK BETWEEN UNEMPLOYMENT AND CAPITAL ACCUMULATION}

To facilitate a detailed quantitative analysis of the relationship between the unemployment rate, $u r$ and the growth rate in the relative capital stock, $r k$ we first examine simple bivariate scatter plots [see Figure 2] for each country. The $r k$ measure is defined as

$$
r k_{t}=\dot{k}_{t}-\Sigma \omega_{j, t} \dot{k}_{j, t},
$$


where, $\dot{k}_{t}$ is a country's own rate of capital stock growth and $\Sigma \omega_{j, t} \dot{k}_{j, t}$ is the GDP weighted sum of the growth rate in the rest of OECD countries ${ }^{8}$.

\section{Figure 2. Unemployment Rate on the Relative Growth of Capital}

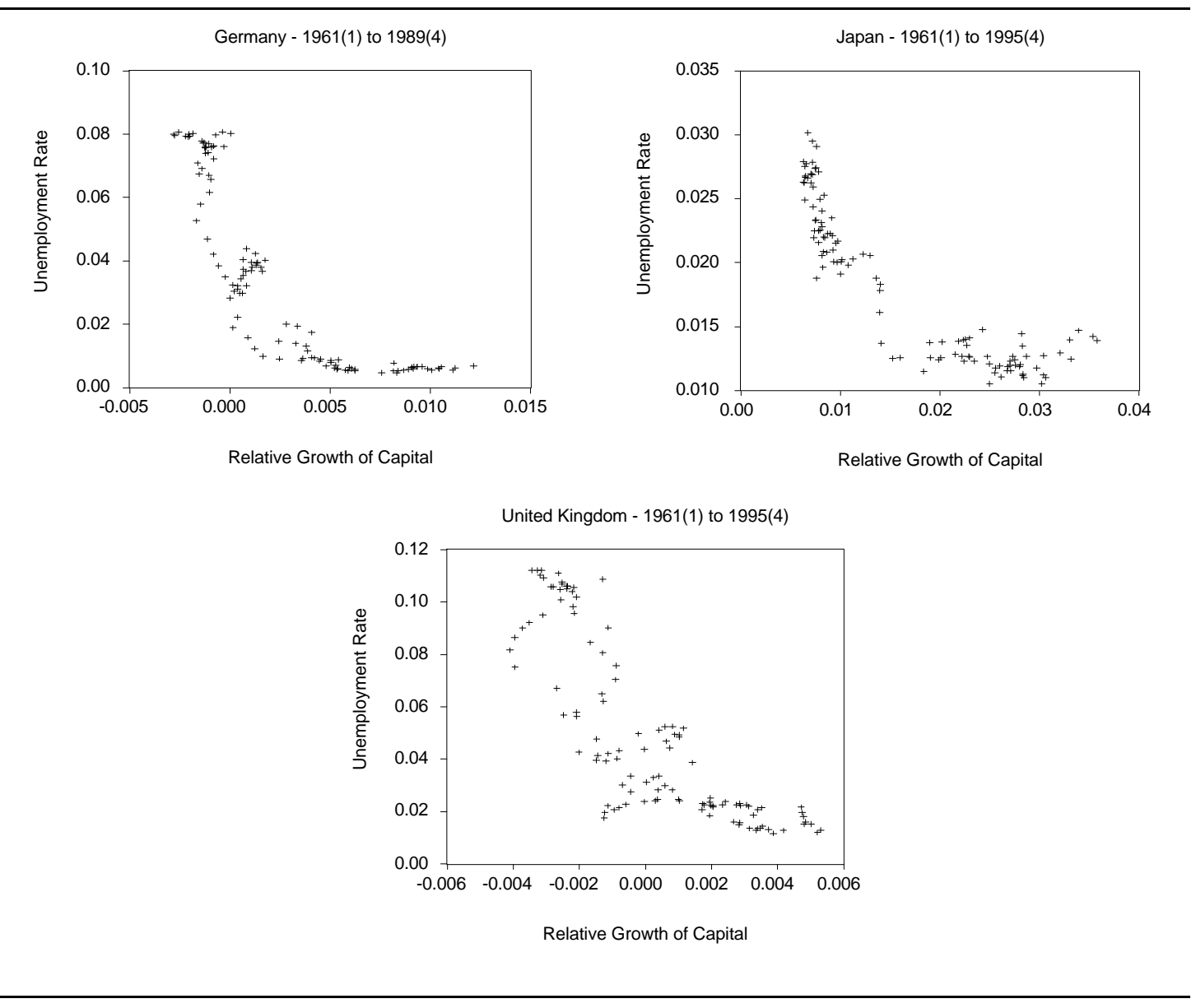

The above scatter plots clearly reveal that the relationship between $u r$ and $r k$ is non-linear. The relationship is nearly vertical at high rates of unemployment [and low rates of relative capital accumulation] and almost horizontal at low rates of unemployment [and high rates of $r k$ ]. This is to be expected since when $u r$ is very low [i.e. when unemployment is mainly frictional] there can be no decreases in the unemployment rate as $r k$ increases. 
Based on the scatter plots we next estimate the following dynamic constant growth model $^{9}$ using nonlinear least squares $[\mathrm{NLS}]^{10}$

$$
\begin{aligned}
& \left(1-\gamma_{p} L^{p}\right) u r_{t}=e^{\alpha+\beta\left(r k_{t-1}\right)}+\varepsilon_{t}, \\
& \varepsilon \sim \operatorname{IID}\left(0, \sigma_{\varepsilon}^{2}\right)
\end{aligned}
$$

where, $\alpha, \beta$, and $\gamma_{p}$ are the parameters to be estimated and $L$ is the lag operator. From the scatter plots and units of measure in Figure 2, $\alpha$ and $\beta$ are both expected to be negative.

Two aspects regarding the specification of (12) are noteworthy. First, a dynamic as opposed to a static model has been employed to capture the inherent delays between capital formation ${ }^{11}$ and its effect on the unemployment rate. In other words, we allow for the effects of $r k$ on $u r$ to be distributed over a number of time periods. Since we do not have apriori information regarding the shape of the lag distribution, the number of time periods, $p$, will be determined statistically instead of being imposed. Note that estimating the lag structure in this fashion provides more flexibility than the simple geometric lag model since it allows for initial change(s) in the lag weight(s) before they taper off and approach zero ${ }^{12}$.

Second, in contrast to the scatter plots which are in terms of contemporaneous $u r$ and $r k$, the above model incorporates a one period lag of $r k$. Although we clearly sacrifice some efficiency by opting for the predetermined value of $r k$, our aim is to avoid inconsistent parameter estimates arising from the potential endogeneity of contemporaneous $r k$. While the endogeneity or exogeneity of $r k$ is commonly treated as a testable assumption, Davidson and McKinnon [1993], more accurately, point out that what is being tested is rather the effect on the parameter estimates of any endogeneity that may be present. For example, using the Durbin-Wu-Hausman 
[DWH] test we can compare NLS, which is efficient [or more efficient] under the null but inconsistent under the alternative, with the NIV [i.e. nonlinear instrumental variables] estimator which is consistent [and less efficient] under both hypotheses. Since the DWH test ${ }^{13}$ requires application of NIV, we need to obtain a valid set of instruments which are correlated with $r k_{t}$ but orthogonal to $\varepsilon_{t}$. Unfortunately, we found the conclusions resulting from application of the DWH test statistic, to be quite sensitive to our choice of instruments ${ }^{14}$. Accordingly our decision to use predetermined $r k$ in (12) with the associated efficiency loss, is a risk averse one reflecting the uncertainty regarding the effect that the potential endogenity of contemporaneous $r k$ has on the NLS parameter estimates.

The estimated dynamic models set out in (12) for Germany, Japan and the United Kingdom are reported above in Table 1. As expected, the estimated values of $\alpha$ and $\beta$ are negative and [more importantly] significant for all countries. Additionally, the models appear to be performing quite satisfactorily with respect to the diagnostic tests of specification and misspecification. To ensure (i) that the significance of predetermined $r k$ was robust to the exclusion of predetermined values of $u r$ and (ii) that the lagged values of $u r$ were not explaining most of the variance in contemporaneous $u r$, we also estimated the static version of (12). From the $\bar{R}^{2}$, s reported in Table 1 we can see that the static model also provides a remarkably good fit to $u r$ and $r k$ data. Additionally, in all countries both parameters of the static model are of a similar magnitude to those in the dynamic model [e.g. for Germany $\alpha=-3.01$ and $\beta=-272.4$; for Japan $\alpha=-3.42$ and $\beta=-37.8$; and for the United Kingdom $\alpha=-3.08$ and $\beta=-164.8]$ and are still significant at the $1 \%$ level. 
Table 1. NLS Estimates of the Basic Dynamic Model in (12) for Germany, Japan and the United Kingdom

\begin{tabular}{llll}
\hline Parameter & Germany & Japan & U.K. \\
Estimates & $\underline{1961(3)-1989(4)^{\S}}$ & $\underline{1961(2)-1995(4)}$ & $\underline{1961(4)-1995(4)}$ \\
$\alpha$ & -6.07 & -5.82 & -6.78 \\
$\beta$ & $(-25.41)^{*}$ & $(-13.64)^{*}$ & $(-17.33)^{*}$ \\
$\beta$ & -251.44 & -42.12 & -135.28 \\
& $(-6.08)^{*}$ & $(-5.30)^{*}$ & $(-3.01)^{*}$ \\
$\gamma_{1}$ & 1.64 & 0.92 & 1.56 \\
& $(17.82)^{*}$ & $(23.33)^{*}$ & $(15.19)^{*}$ \\
$\gamma_{2}$ & -0.68 & $n s$ & -0.36 \\
& $-(7.77)^{*}$ & & $(-2.05)^{* *}$ \\
$\gamma_{3}$ & $n s$ & $n s$ & -0.22 \\
& & & $(-2.82)^{*}$ \\
$\bar{R}^{2}$ & & 0.98 & \\
$\bar{R}^{2}[$ Static Model] & 0.87 & 0.83 & 0.99 \\
$S . E$. & 0.001 & 0.0001 & 0.66 \\
$S_{1}$ & $0.00[0.947]$ & $0.00[0.959]$ & 0.002 \\
$S_{2}$ & $1.28[0.528]$ & $2.09[0.353]$ & $0.90[0.343]$ \\
$S_{3}$ & $2.20[0.532]$ & $3.20[0.362]$ & $1.23[0.541]$ \\
$S_{4}$ & $4.59[0.332]$ & $3.61[0.461]$ & $1.85[0.604]$ \\
$T_{1}$ & $0.03[0.856]$ & $2.84[0.092]$ & $0.01[0.556]$ \\
$T_{2}$ & $0.27[0.606]$ & $4.22[0.040]$ & $1.17[0.532]$ \\
\hline
\end{tabular}

- $\S$ The German sample is truncated to 1989(4) due to reunification.

- Numbers in parentheses are t-ratios based on White's heteroscedastic consistent standard errors.

- *, and ** indicate significance at the 1 and 5 percent levels respectively.

- Number in square brackets are probability values.

- $n s$ indicates not significant at the $5 \%$ level.

- $\mathrm{S}_{1}$ to $\mathrm{S}_{4}$ : Lagrange Multiplier tests for $1^{\text {st }}$ to $4^{\text {th }}$ order autocorrelation, distributed asymptotically as $\chi^{2}(1)$ to $\chi^{2}(4)$.

- $\mathrm{T}_{1}$ : RESET test, distributed asymptotically as $\chi^{2}(1)$.

- $T_{2}$ : Heteroscedasitcity test, distributed asymptotically as $\chi^{2}(1)$.

Given the nonlinear functional form employed in the basic dynamic model, to discover how changes in the rate of relative capital accumulation effects the unemployment rate in the steady-state, we need to simulate the model for each country. Our simulations show the effects on the unemployment rate resulting from a permanent increase in $r k$ by one percentage point. The results of this exercise reported in Figure 4 above show that the expected steady-state reductions in the unemployment rate resulting from the shock are about $0.4,0.8$ and 1.0 percentage points for 
Germany, Japan and the United Kingdom respectively. Additionally, the Figure indicates that it takes approximately 5, 15 and 12 years for Germany, Japan and the United Kingdom respectively to reach their new steady state values after the shock.

Figure 4. Unemployment Rate Changes Resulting from a Permanent $1 \%$ Point Increase in the Rate of Relative Capital Accumulation
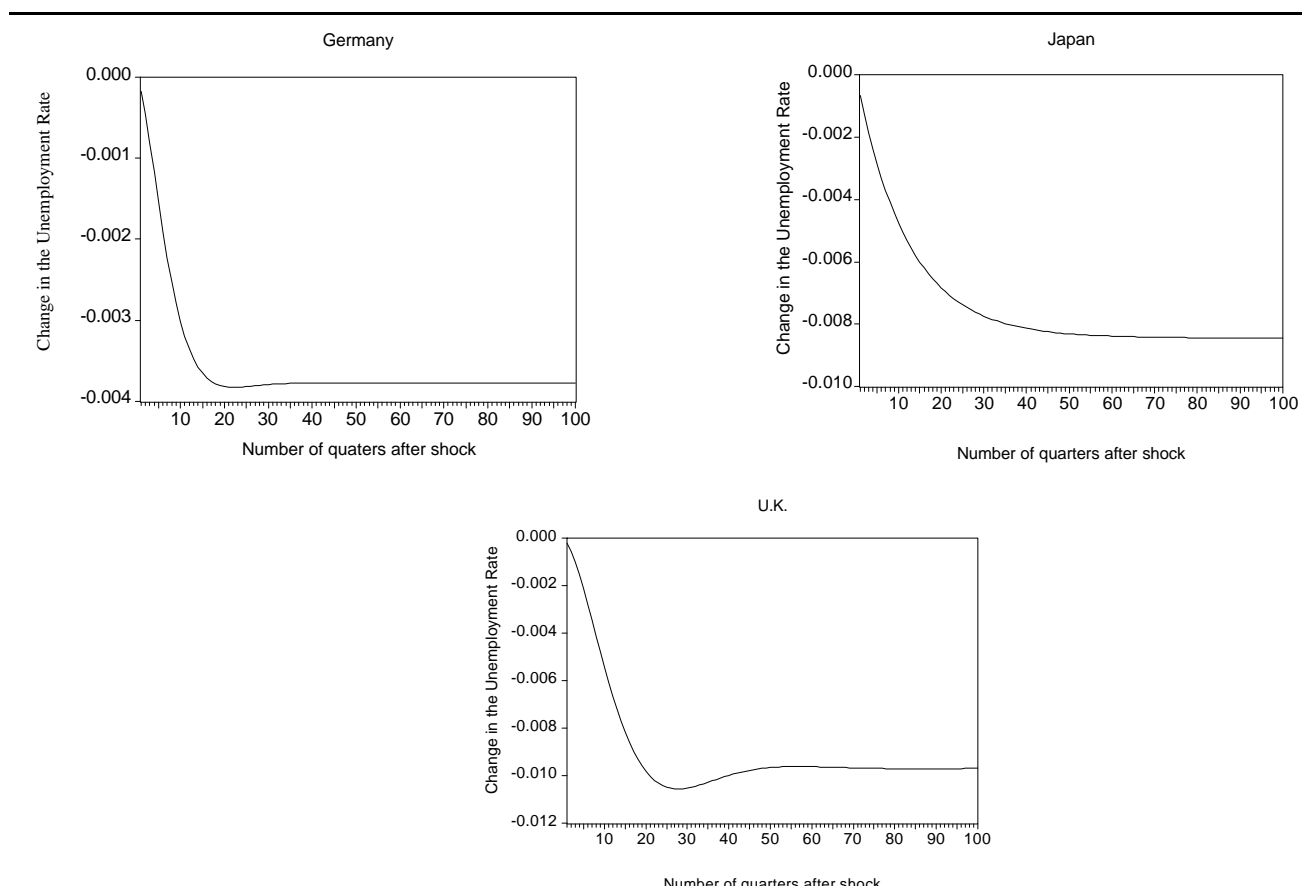

IV. EXTENSIONS OF THE BASIC DYNAMIC MODEL

Having established the statistical importance of $r k$ as a determinant of $u r$ and the macroeconomic implications of competitiveness [i.e. relative unit labour costs] and the labour force on $u r$ [see Section 2.2], we next examine to what extent the evolution of the latter two variables can either augment or supplant the negative relationship between $u r$ and $r k$. Additionally to test whether $r k$ may be inadvertently acting as a proxy for traditional aggregate demand arguments we include the rates of growth in domestic aggregate demand and in the rest of the OECD as possible determinants of the unemployment rate. 
To assess the importance of these extensions, we re-estimate (12) using a stepwise regression procedure to determine whether lagged growth in the labour force, $\dot{L} f$, own GDP, $\dot{y}$, Rest of OECD [ROECD] GDP, $\dot{y}^{*}$ and competitiveness, $\dot{c}$ enter the basic dynamic model. Predetermined values for each variable are again employed for the same reasons given in Section 3 for using lagged $r k$. The general model implied by the above extensions is given by

$$
\left(1-\gamma_{p} L^{p}\right) u r_{t}=e^{\alpha+\beta\left(r k_{t-1}\right)}+\delta_{1} \dot{L} f_{t-1}+\delta_{2} \dot{y}_{t-1}+\delta_{3} \dot{y}_{t-1}^{*}+\delta_{4} \dot{c}_{t-1}+\mu_{t} .
$$

The extra regressors are added linearly in (13) for each country, since (i) scatter plots of the unemployment rate on each of the extra arguments and (ii) scatter plots of the residuals from equation (12) on each of the additional variables did not reveal any nonlinearities ${ }^{15}$.

The stepwise search algorithm we employ proceeds through a combination of forward and backward variable selection. Starting with the basic dynamic model in (12), we first fit four different regression models [i.e. equation (12) plus each of the "extra" conditioning variables in turn]. We next examine the heteroscedastic consistent t-ratio for the extra variable in each model. If the 0.05 probability level value is achieved, that variable is added to the basic model given by (12). Following this we next check whether any of the variables from the basic dynamic model [i.e. $r k_{t-l}$ and predetermined values of $\left.u r\right]$ should be dropped. If an "extra" variable enters at stage- 1 we next fit all two variable combinations for the remaining variables and repeat the above procedure for deleting and adding variables until no further variables can be either included or excluded. 
Given that both the values of the estimated regression coefficients and their standard errors depend on the covariance between the conditioning variables, a robust outcome to the above variable selection procedure relies on the lack of high correlation between the regressors. Examination of the correlations in Table 2 reveals that the stepwise search procedure should produce sensible outcomes in that the variables considered are orthogonal to one another. Further evidence supporting this conclusion is presented below where we provide a comparison of the outcomes of the stepwise selection method with those from a general-to-specific selection strategy.

Table 2. Correlation Matrices for the Conditioning Variables

\begin{tabular}{|c|c|c|c|c|c|c|c|c|c|c|c|}
\hline \multirow[b]{3}{*}{$r k$} & \multicolumn{5}{|c|}{ Germany 1965(2)-1989(4) } & \multicolumn{6}{|c|}{ Japan 1965(2)-1989(4) } \\
\hline & $r k$ & $\dot{L} f$ & $\dot{y}$ & $\dot{y}^{*}$ & $\dot{c}$ & \multirow[b]{2}{*}{$r k$} & \multirow{2}{*}{$\begin{array}{l}r k \\
1.00\end{array}$} & \multirow{2}{*}{$\dot{L} f$} & \multirow[t]{2}{*}{$\dot{y}$} & \multirow[t]{2}{*}{$\dot{y}^{*}$} & \multirow[t]{2}{*}{$\dot{c}$} \\
\hline & 1.00 & & & & & & & & & & \\
\hline$\dot{L} f$ & -0.16 & 1.00 & & & & $\dot{L} f$ & 0.06 & 1.00 & & & \\
\hline$\dot{y}$ & 0.29 & 0.10 & 1.00 & & & $\dot{y}$ & 0.55 & 0.27 & 1.00 & & \\
\hline$\dot{y}^{*}$ & 0.12 & -0.15 & 0.13 & 1.00 & & $\dot{y}^{*}$ & 0.09 & 0.03 & 0.15 & 1.00 & \\
\hline$\dot{c}$ & 0.25 & 0.13 & 0.12 & 0.21 & 1.00 & $\dot{c}$ & -0.05 & -0.04 & -0.12 & 0.20 & 1.00 \\
\hline \multicolumn{12}{|c|}{ U.K. $1965(2)-1995(4)$} \\
\hline & & & & $r k$ & $\dot{L} f$ & $\dot{y}$ & $\dot{y}^{*}$ & $\dot{c}$ & & & \\
\hline & & & $r k$ & 1.00 & & & & & & & \\
\hline & & & $\dot{L} f$ & -0.05 & 1.00 & & & & & & \\
\hline & & & $\dot{y}$ & 0.09 & 0.10 & 1.00 & & & & & \\
\hline & & & $\dot{y}^{*}$ & 0.03 & 0.09 & 0.16 & 1.00 & & & & \\
\hline & & & $\dot{c}$ & -0.02 & 0.12 & -0.19 & -0.06 & 1.00 & & & \\
\hline
\end{tabular}

- Note that these estimations start in 1965(2) instead of 1961(1) since the labour force level is not reported in the OECD Quarterly Labour Force Statistics database prior to 1965(1). 
Table 3. First Stage of the Stepwise Specification Strategy

\begin{tabular}{llll}
\hline \multirow{4}{*}{ Parameters } & \multicolumn{3}{c}{ Basic DynamicModel } \\
& Germany & Japan & U.K. \\
$\alpha$ & $1965(3)-1989(4)$ & $1965(3)-1995(4)$ & $1965(3)-1995(4)$ \\
$\beta$ & $-6.08[0.000]$ & $-5.85[0.000]$ & $-6.74[0.000$ \\
$\gamma_{1}$ & $-252.6[0.000]$ & $-43.54[0.000]$ & $-124.3[0.009]$ \\
$\gamma_{2}$ & $1.60[0.000]$ & $0.92[0.000]$ & $1.75[0.000]$ \\
& $-0.70[0.000]$ & $n s$ & $-0.77[0.000$
\end{tabular}

Basic DynamicModel + Lagged Labour Force Growth

\begin{tabular}{|c|c|c|c|}
\hline Parameters & Germany & Japan & $U . K$. \\
\hline$\alpha$ & $-6.07 \quad[0.000]$ & $-5.85 \quad[0.000]$ & $-6.74[0.000]$ \\
\hline$\beta$ & $-252.7[0.000]$ & $-42.12[0.000]$ & $-119.7[0.014]$ \\
\hline$\gamma_{1}$ & $1.65[0.000]$ & $0.92[0.000]$ & $1.74[0.000]$ \\
\hline$\gamma_{2}$ & $-0.70 \quad[0.000]$ & $n s$ & $-0.77[0.000]$ \\
\hline$\delta_{1}$ & $-0.001[0.977]$ & $-0.01 \quad[0.604]$ & $-0.04[0.519$ \\
\hline
\end{tabular}

Basic DynamicModel + Lagged GDP Growth

\begin{tabular}{|c|c|c|c|}
\hline Parameters & Germany & Japan & $U . K$. \\
\hline$\alpha$ & $-5.98[0.000]$ & $-6.02[0.000]$ & $-6.69[0.000]$ \\
\hline$\beta$ & $-176.3[0.004]$ & $-30.40[0.020]$ & $-106.9[0.040]$ \\
\hline$\gamma_{1}$ & $1.55[0.000]$ & $0.93[0.000]$ & $1.72[0.000]$ \\
\hline$\gamma_{2}$ & $-0.59[0.000]$ & $n s$ & $-0.74 \quad[0.000]$ \\
\hline$\delta_{2}$ & $-0.05[0.055]$ & $-0.01 \quad[0.124]$ & $-0.03[0.142]$ \\
\hline
\end{tabular}

Basic DynamicModel + Lagged ROECD GDP Growth

\begin{tabular}{llllll} 
Parameters & \multicolumn{2}{l}{ Germany } & \multicolumn{2}{l}{ Japan } & U.K. \\
$\alpha$ & $-6.09[0.000]$ & $-5.87[0.000]$ & -6.69 & {$[0.000]$} \\
$\beta$ & $-250.2[0.000]$ & $-43.35[0.000]$ & $-122.9[0.008]$ \\
$\gamma_{1}$ & $1.65[0.000]$ & $0.93[0.000]$ & 1.74 & {$[0.000]$} \\
$\gamma_{2}$ & $-0.69[0.000]$ & $n s$ & -0.76 & {$[0.000]$} \\
$\delta_{3}$ & $-0.01[0.496]$ & $-0.001[0.877]$ & -0.01 & {$[0.387]$}
\end{tabular}

Basic DynamicModel + Lagged Competitiveness Growth

\begin{tabular}{|c|c|c|c|}
\hline Parameters & Germany & Japan & U.K. \\
\hline$\alpha$ & $-6.10[0.000]$ & $-5.69[0.000]$ & $-6.79[0.000]$ \\
\hline$\beta$ & $-266.2[0.000]$ & $-43.40[0.000]$ & $-125.5[0.011]$ \\
\hline$\gamma_{1}$ & $1.67[0.000]$ & $0.91[0.000]$ & $1.74[0.000]$ \\
\hline$\gamma_{2}$ & $-0.72[0.000]$ & $n s$ & $-0.76[0.000]$ \\
\hline$\delta_{4}$ & $-0.01[0.148]$ & $0.01 \quad[0.013]$ & $0.01[0.118]$ \\
\hline
\end{tabular}

- Note that these estimations start in 1965(3) instead of 1961(1) due to the lack of labour force data.

- As in Table 1, the number of lags, $p$ in the basic dynamic model is determined statistically.

- The numbers in square brackets are probability values used to determine the significance of the heteroscedastic consistent t-ratios. 
Tables 3 and 4 report the first and final stages of applying the stepwise regression procedure described above. Examination of Table 3 shows, with the exception of competitiveness for Japan, that none of the additional conditioning variables enters the basic dynamic model in equation (12) at the 5\% significance level. Additionally none of the variables from the basic dynamic model are variance dominated or rendered insignificant by the inclusion of the extra regressors.

Table 4. Final Models Selected Using the Stepwise Specification Strategy

\begin{tabular}{|c|c|c|}
\hline \multicolumn{3}{|c|}{ Basic DynamicModel } \\
\hline Parameters & $\begin{array}{l}\text { Germany } \\
\text { 1965(3)-1989(4) }\end{array}$ & $\begin{array}{l}\text { Germany } \\
\text { 1961(3)-1989(4) }\end{array}$ \\
\hline$\alpha$ & $-6.08 \quad[0.000]$ & $-6.07[0.000]$ \\
\hline$\beta$ & $-252.6[0.000]$ & $-251.4[0.000]$ \\
\hline$\gamma_{1}$ & $1.65[0.000]$ & $1.64[0.000]$ \\
\hline$\gamma_{2}$ & $-0.70 \quad[0.000]$ & $-0.68[0.000]$ \\
\hline
\end{tabular}

$\underline{\text { Basic DynamicModel + Lagged Competitiveness Growth }}{ }^{\S}$

\begin{tabular}{|c|c|c|}
\hline \multirow[t]{2}{*}{ Parameters } & Japan & Japan \\
\hline & $1965(3)-1995(4)$ & $1962(4)-1995(4) \S$ \\
\hline$\alpha$ & $-5.69[0.000]$ & $-5.63[0.000]$ \\
\hline$\beta$ & $-43.40[0.000]$ & $-42.63[0.000]$ \\
\hline$\gamma_{1}$ & $0.91[0.000]$ & $0.90 \quad[0.000]$ \\
\hline$\delta_{4}$ & $0.01 \quad[0.013]$ & $0.01 \quad[0.011]$ \\
\hline \multicolumn{3}{|c|}{ Basic DynamicModel } \\
\hline Parameters & $\begin{array}{l}U . K . \\
1965(3)-1995(4)\end{array}$ & $\begin{array}{l}U . K . \\
1961(4)-1995(4)\end{array}$ \\
\hline$\alpha$ & $-6.74[0.000]$ & $-6.78[0.000]$ \\
\hline$\beta$ & $-124.3[0.009]$ & $-135.3[0.000]$ \\
\hline$\gamma_{1}$ & $1.75[0.000]$ & $1.56 \quad[0.000]$ \\
\hline$\gamma_{2}$ & $-0.77 \quad[0.000]$ & $-0.36[0.042]$ \\
\hline$\gamma_{3}$ & $n s$ & $-0.22[0.006]$ \\
\hline
\end{tabular}

\footnotetext{
- " Note that lagged own GDP growth which was nearly significant at the 5\% level in Germany [i.e. $\mathrm{p}$-value $=0.055$ ] over the 1965(3)-1989(4) estimation period is not significant [i.e. $\mathrm{p}$-value= 0.075] over 1961(3)-1989(4) estimation period.

$-{ }^{\varsigma}$ Given the extremely small changes in $\alpha, \beta$, and $\gamma$ for Japan reported in this Table relative to their values in Table 1 [i.e. when competitiveness is excluded], re-simulating the model reported in Figure 4, not surprisingly, does not produce discernibly different results.

- $\S$ This regression starts in 1962(4) instead of 1961(2) since competitiveness is not available prior to $1962(3)$.
} 
Continuing with the forward and backward selection procedure described above for Japan yields the final model reported in Table 4 which shows that only competitiveness is retained. In addition to the shorter time period used for the estimation in Table 3, [due to insufficient labour force data], Table 4 also reports the estimations for the longer time period used in Table 1. The latter is possible since the labour force is not an included regressor in any of the models.

In contrast to the above variable selection strategy, in Table 5, we start by estimating the most general model [i.e. the basic dynamic model plus all four extra conditioning variables]. As expected, the t-values for the parameters of the basic dynamic model will be smaller than those of Table 1 since (i) the number of observations used for the estimation in Table 5 is less than in Table 1 and (ii) the number of regressors has increased. However, several points regarding the estimates in Table 5 are noteworthy. First, using the Wald test [based on the adjusted covariance matrix], the joint restriction of zero effect for the new regressors as a set can only be rejected for Japan. Examination of the individual heteroscedastic consistent t-statistics and associated probability levels reveals that this is clearly due to the individual importance of the competitiveness argument for Japan. Second, none of the extra regressors is individually more significant than the regressors in the original dynamic model. Finally, we find that sequential reduction of the general model carried out by dropping the least significant variable first leads to the same final model as in column 1 of Table 4.

The absence of the domestic and rest of the OECD demand measures as determinants of the unemployment rate is noteworthy. It establishes that even in a fast growing world economy only those countries which have higher rates of capital 
accumulation than their trade partners can expect lower unemployment rates. It also provides indirect evidence that the ex-post substitutability between capital and labour is not large.

Table 5. First Stage of General to Specific Specification Strategy

\begin{tabular}{lllllll}
\hline \multirow{2}{*}{ Parameters } & \multicolumn{4}{c}{ Basic DynamicModel } & \\
& \multicolumn{1}{l}{ Germany } & Japan & & U.K. \\
$\alpha$ & $-565(3)-1989(4)$ & & $\underline{1965(3)-1995(4)}$ & & $\underline{1965(3)-1995(4)}$ \\
& -5.99 & -5.84 & -6.72 & \\
$\beta$ & $(-23.7)$ & {$[0.000]$} & $(-9.8)$ & {$[0.000]$} & $(-16.4)$ & {$[0.000]$} \\
& -193.0 & & -34.64 & -101.1 & \\
$\gamma_{1}$ & $(-3.1)$ & {$[0.003]$} & $(-2.89)$ & {$[0.005]$} & $(-1.84)$ & {$[0.068]$} \\
& 1.57 & & 0.92 & & 1.70 & \\
$\gamma_{2}$ & $(17.8)$ & {$[0.000]$} & $(17.7)$ & {$[0.000]$} & $(23.9)$ & {$[0.000]$} \\
& -0.61 & & $n s$ & & -0.72 & \\
& $(-7.2)$ & {$[0.000]$} & & & $(-10.1)$ & {$[0.000]$}
\end{tabular}

Wald Test of the Joint Restriction, $\boldsymbol{\delta}_{1}=\underline{\delta}_{2} \underline{\underline{\delta}}_{3}=\underline{\delta}_{4}=0$

\begin{tabular}{|c|c|c|}
\hline & Germany & Japan \\
\hline est Statistic & $8.47[0.076]$ & $9.47[0.050]$ \\
\hline
\end{tabular}

Marginal Significance of Extra Regressors

\begin{tabular}{llllllll} 
Parameters & \multicolumn{2}{l}{ Germany } & Japan & & & U.K. \\
S $\delta_{1}$ & -0.01 & & -0.004 & & -0.06 & \\
& $(-0.39)$ & {$[0.695]$} & $(-0.13)$ & {$[0.893]$} & $(-0.94)$ & {$[0.350]$} \\
$\delta_{2}$ & -0.05 & & -0.01 & & -0.02 & \\
& $(-1.87)$ & {$[0.065]$} & $(-0.98)$ & {$[0.329]$} & $(-1.18)$ & {$[0.241]$} \\
$\delta_{3}$ & -0.01 & & -0.002 & & -0.01 & \\
& $(-1.01)$ & {$[0.314]$} & $(-0.56)$ & {$[0.574]$} & $(-0.71)$ & {$[0.477]$} \\
$\delta_{4}$ & 0.02 & & 0.01 & & 0.01 & \\
& $(1.66)$ & {$[0.101]$} & $(2.37)$ & {$[0.019]$} & $(1.47)$ & {$[0.146]$}
\end{tabular}

\section{CONCLUDING REMARKS}

Our findings suggest that the widely differing experiences of Germany, Japan and the United Kingdom with regard to the evolution of their capital stock relative to the rest of the OECD capital stock is very important in explaining their vastly differing unemployment rate experiences over the last thirty-five years. Our explanation for this 
phenomenon is essentially a supply-side one: an increase in the domestic capital stock relative to the foreign capital stock allows domestic firms to compete more effectively and to capture market share at the expense of foreign firms. Equiproportional increases in the domestic and foreign capital stock essentially move both countries upwards along a vertical long-run wage-setting curve. Real wages increase in both countries but the unemployment rate in the very long-term is unaffected. However, if the domestic country accumulates capital at a slower pace than the foreign country it will suffer - ceteris paribus - higher unemployment rates than the foreign country for prolonged periods of time. This may eventually induce downward shifts of the shortto-medium-term upward sloping wage setting schedule, thereby preventing a continuous upward movement of the unemployment rate ${ }^{16}$. In other words, this paper explains the medium- to long-term variations [caused by differential rates of capital accumulation] around the untrended very long-term unemployment rate brought to the attention of the profession by LNJ [1991].

There is, however, an important difference between the policy conclusions drawn by LNJ [1991] and this paper. They downplay the importance of capital accumulation. To them "the main social institutions that affect unemployment are the unemployment benefit system and the system of wage determination" [LNJ, 1991, p.3]. Although we do not want to argue about the importance of these factors, we want to note that our results indicate that a complete understanding of their effects on the unemployment rate must take account of how they influence the rate of relative capital accumulation $^{17}$. In any case, our results indicate that policies which encourage a faster rate of capital accumulation should be a necessary component of any policy package aimed at reducing unemployment. 


\section{REFERENCES}

Alogoskoufis, G. and R. Smith, "The Phillips Curve, the Persistence of Inflation, and the Lucas Critique: Evidence from Exchange-Rate Regimes", American Economic Review, 81, 1991, 1254-75.

Alogoskoufis, G., Bean, C., Bertola, G., Cohen, D., Dolado, J., and G. Saint-Paul, Unemployment: Choices for Europe, (CEPR, London, 1995).

Bean, C.R., "European Unemployment: A Survey", Journal of Economic Literature, 32, 1994, 573-619.

Blanchard, O.J., "Revisiting European Unemployment, Unemployment, Capital Accumulation, and Factor Prices", mimeo, (Massachusetts Institute of Technology, 1998).

Blanchard, O.J., “The Medium Run”, Brookings Papers on Economic Activity, 2, 1997, 89-158.

Blanchard, O.J., "The Wage-Price Spiral”, Quarterly Journal of Economics, 101, 1986, 543-65.

Brander, J. and B. Spencer, "Export Subsides and Market Share Rivalry", Journal of International Economics, 18, 1985, 83-100.

Carlin, W. and D. Soskice, Macroeconomics and the Wage Bargain, (Oxford University Press, Oxford, 1990).

Daveri, F. and G. Tabellini, "Unemployment, Growth and Taxation in Industrial Countries”, (CEPR Discussion Paper No, 1681, 1997).

Davidson, R. and J. McKinnon, Estimation and Inference in Econometrics, (Oxford University Press, Oxford, 1993).

Dräze, J.H. and C.R. Bean, Europe's Unemployment Problem, (MIT Press, Cambridge, MA, 1990).

Gordon, R., "Is There a Trade-Off Between Unemployment and Productivity Growth", in D.J. Snower and G. de la Dehesa (eds) Unemployment Policy: Government Options for the Labour Market, (CU Press, Cambridge, 1997).

Jorgenson, D., "Rational Distributed Lag Functions”, Econometrica, 34, 1966, 135149.

Helpman, E. and P. Krugman, 1989, Trade Policy and Market Structure, (MIT Press, Cambridge, MA, 1989).

Layard, R.S. and S. Nickell, "Unemployment in Britain”, Economica, 53, 1986, 121 169. 
Layard, R.S., Nickell, S. and R. Jackman, Unemployment: Macroeconomic Performance and the Labour Market, (Oxford University Press, Oxford, 1991).

Lindbeck, A. and D.J. Snower, The Insider-Outsider Theory of Employment and Unemployment, (MIT Press, Cambridge, MA, 1988).

Ljungqvist, L. and T. Sargent, "The European Unemployment Dilemma, Journal of Political Economy”, 106, 1988, 514-550.

Malinvaud , E., Profitability and Unemployment, (Cambridge University Press, Cambridge, 1980).

Nickell, S., "Unemployment: Questions and Some Answers", Economic Journal, 108, 1998, 802-816.

Nickell, S., "Unemployment and Labor Market Rigidities: Europe versus North America", Journal of Economic Perspectives, 11, 1997, 55-74.

Phelps, E. and G. Zoega, "Natural-Rate Theory and OECD Unemployment", Economic Journal, 108, 1998, 782-801.

Rowthorn, R., "Conflict, Inflation and Money", Cambridge Journal of Economics, 1, 1977, 215-239.

Rowthorn, R., "Capital Formation and Unemployment”, Oxford Review of Economic Policy, 11, 1996, 26-39.

Siebert, H., "Labor Market Rigidities: At the Root of Unemployment in Europe", Journal of Economic Perspectives, 11, 1997, 37-54.

Sneessens, H.R. and J.H. Dräze, “A Discussion of Unemployment, Comparing Traditional Concepts and Disequilibrium Economics", Economica, Supplement, 53, 1996, S89-119. 
VII. Data Appendix

\begin{tabular}{|c|c|c|}
\hline Variables & Definitions & Sources \\
\hline$\overline{u r}$ & unemployment rate & $\mathrm{BSD}$ \\
\hline$r k_{t}=\dot{k}_{t}-\Sigma \omega_{j, t} \dot{k}_{j, t}$ & relative rate of capital accumulation & transformation \\
\hline$\dot{k}_{t}$ & own rate of capital stock growth & BSD \\
\hline \multirow[t]{2}{*}{$\Sigma \omega_{j, t} \dot{k}_{j, t}$} & \multicolumn{2}{|l|}{ weighted sum of real capital stock growth } \\
\hline & in Rest of OECD [ROECD] & transformation \\
\hline$\omega_{j, t}$ & real GDP weights in ROECD & transformation \\
\hline$\dot{L} f_{t}$ & labour force growth & QLF \\
\hline$\dot{y}_{t}$ & real GDP growth & BSD \\
\hline$\dot{y}_{t}^{*}$ & ROECD real GDP growth & BSD \\
\hline$\dot{c}_{t}$ & $\begin{array}{l}\text { competitiveness [relative unit labour } \\
\text { cost manufacturing, common currency] }\end{array}$ & EO \\
\hline \multicolumn{3}{|c|}{$\begin{array}{l}\text { - Note that the } 25 \text { OECD countries include Australia, Austria, Belgium, Canada, Switzerland, } \\
\text { Germany, Denmark, Spain, Finland, France, Great Britain, Greece, Ireland, Iceland, Italy, Japan, } \\
\text { Luxembourg, Mexico, New Zealand, Netherlands, Norway, Portugal, Sweden, Turkey, United } \\
\text { States. However, four countries were not included due either to not reporting any capital stock data } \\
\text { [e.g. Turkey \& Mexico] or insufficient coverage for capital stock [e.g. Iceland's data starts in } 1979 \\
\& \text { New Zealand's in 1981] or insufficient coverage for the unemployment rate [e.g. Luxembourg's } \\
\text { data starts in 1974]. } \\
\text { - BSD, QLF and EO refer to the OECD Business Sector, Quarterly Labour Force Statistics and } \\
\text { Economic Outlook Databases respectively. }\end{array}$} \\
\hline
\end{tabular}




\section{ENDNOTES}

\footnotetext{
${ }^{1}$ Data availability constrains us to use the rest of OECD as a proxy for the rest of the world. The sample period for the German data has been truncated to 1989(4) due to reunification.

${ }^{2}$ Full sample data are not available for Iceland, Luxembourg, Mexico, New Zealand and Turkey.

${ }^{3}$ Controlling for changes in labour supply - as we do later in the paper for the three countries on which we concentrate - may reveal that the same relationship between the unemployment rate and the growth in relative capital accumulation holds for these countries as well.
}

${ }^{4}$ Needless to say that other partial equilibrium models with different assumptions about market structure would yield the same conclusions.

${ }^{5}$ Alternatively it can induce more inward migration thereby again increasing the labour force.

${ }^{6}$ This can be a different explanation for the fact that the unemployment rate is untrended over very long periods of time.

${ }^{7}$ The data employed in this study are on a quarterly basis and are from the OECD Business Sector [BSD], Quarterly Labour Force Statistics [QLF] and Economic Outlook [EO] databases. Further details on data definitions and sources can be found in the Data Appendix.

${ }^{8}$ Note that when constructing the common currency GDP weights, current quarterly exchange rates in each period are employed. The resulting time series of GDP weights instead of a fixed or chained weights is then applied to the time-series of capital stock growth for each country. Further note that using the fixed or chained GDP weighted alternatives [constructed with either fixed or variable exchange rates] did not alter our econometric findings reported below.

${ }^{9}$ Obvious nonlinear alternatives, which are capable of approximating the rectangular hyperbolic shape in Figure 2, include the constant elasticity and the reciprocal models. However since rk can take on negative values, the constant elasticity model is not applicable. Additionally, we found that the reciprocal model, commonly used to estimate Phillips curves [see, for example, Alogoskoufis and Smith, 1991], provides a substantially worse fit for all countries.

${ }^{10}$ Note that although application of NLS in this context is subject to finite sample bias [since $u r_{t-1}$ is not orthogonal to $\left.\varepsilon_{t+1}, \varepsilon_{t+2} \ldots, \varepsilon_{t+T}\right]$ it will be consistent as long as the errors are serially uncorrelated.

${ }^{11}$ Table 1 and page 17 contain details relating to the overall fit and significance tests for the parameters of the static model.

${ }^{12}$ Clearly the rational lag model [see Jorgenson, 1966] would provide even greater flexibility in estimating the unknown lag structure. However we found this unnecessary since additional lags of $r k$ proved to be insignificant for all countries.

13 Calculated as follows: $D W H=\left(\mathbf{b}_{N L S}-\mathbf{b}_{N I V}\right)^{\prime}\left(\Sigma_{N L S}-\Sigma_{N I V}\right)^{-1}\left(\mathbf{b}_{N L S}-\mathbf{b}_{N I V}\right) \sim \chi^{2}(k)$, where $\mathbf{b}_{\mathrm{NLS}} \mathbf{b}_{\mathrm{NIV}}$ are the vectors of estimated parameters of NLS and NIV respectively, $\Sigma_{N L S}, \Sigma_{N I V}$ are the estimated variance covariance matrices of NLS and NIV respectively and k refers to the degrees of freedom which are equal to the rank of $\left(\Sigma_{N L S}-\Sigma_{N I V}\right)$.

${ }^{14}$ In addition to using predetermined $u r$ and $r k$ we also experimented with contemporaneous and/or lagged values of the growth in the labour force, the real wage, own GDP, rest of OECD GDP and relative unit labour costs. 
${ }^{15}$ These twenty four scatter plots are not presented to preserve space but will be made available on request.

${ }^{16}$ For an explanation of why the wage setting schedule by be vertical in the long-run see Lindbeck and Snower [1988].

${ }^{17}$ For example, Daveri and Tabellini [1997] provide evidence of how the system of wage determination, by stifling the incentives for firms to accumulate capital in the face of higher labour taxes, can contribute to higher unemployment.

July 1998 [Revised Oct. 1998]

Jim Malley, Department of Economics, University of Glasgow, Glasgow G12 8RT, UK, email: j.malley@socsci.gla.ac.uk.

Thomas Moutos, Department of International \& European Economic Studies, Athens tmoutos@aueb.gr. 